\title{
Sistem Monitoring Konsumsi Daya Listrik Dengan Mengimplementasikan Bluetooh Low Energy
}

\author{
Pezi Apriliani, Budi Rahmadya, Derisma \\ Jurusan Sistem Komputer, FTI Universitas Andalas Limau Manis Kec. Pauh, Kota Padang, Sumatera Barat 25163 INDONESIA
}

\section{ARTICLE INFORMATION}

Received: February $9^{\text {th }}, 2021$

Revised: March $12^{\text {th }}, 2021$

Available online: March $31^{\text {st }}, 2021$

\section{KEYWORDS}

Kwh Meter Prabayar, Sensor Arus SCT 013, Bluetooth Low Energy, Daya Listrik.

\section{CORRESPONDENCE}

Budi Rahmadya

E-mail: budi-r@fti.unand.ac.id

\section{A $\quad$ B $\quad S \quad T \quad R A$ C $\mathbf{T}$}

\begin{abstract}
Electricity becomes a major need for human in this era. PLN's electricity payment system in residential areas is divided into two ways, postpaid electricity and prepaid electricity. Prepaid electricity using digital kWh meter that shows the use of current, electric power, etc on LCD. The usage of current and electric power can be monitored using Android application using Bluetooth Low Energy (BLE) as communication media. BLE has many advantages module compared to classic bluetooth, for example having a wider range, data transfer speeds up to $1 \mathrm{Mbps}$, and low power consumption. Therefore the writer researched by implementing Bluetooth Low Energy in the electric power monitoring system. The results of this research showed that the electric power monitoring system and the BLE module could send the result of sensor measurement to android applications. From the testing that has been done showed that the BLE send module can be up to 25 meters distance for unhindered conditions and 8 meters with hindered conditions. And the BLE module energy consumption is more efficient than HC-05 energy comparison BLE module 5,728 $\mathrm{mW}$ and the HC-05 module $13.47 \mathrm{~mW}$.
\end{abstract}

\section{PENDAHULUAN}

Listrik menjadi kebutuhan pokok bagi manusia pada saat sekarang ini. Sistem pembayaran listrik PLN yang ada pada perumahan masyarakat terbagi atas dua macam, yaitu listrik pascabayar dan listrik prabayar. Pada listrik prabayar menggunakan kwh meter digital yang dapat menampilkan penggunaan arus, daya listrik, dan lain-lain pada lcd. Penggunaan arus dan daya listrik dapat dimonitoring menggunakan aplikasi android dengan menggunakan Bluetooth Low Energy (BLE) sebagai media komunikasi.

Pada penelitian sebelumnya oleh Afriadi[1], membahas tentang pengendalian dan monitoring biaya pemakaian listrik peralatan elektronik rumah tangga dengan menggunakan aplikasi pada smartphone sebagai sistem kontrol. Pada penelitian ini digunakan sensor arus ACS712 untuk mengukur arus pada lampu pijar dan televisi dengan menggunakan bluetooth sebagai media komunikasi. Hasil penelitian menunjukkan nilai error pembacaan arus yaitu sebesar $13,89 \%$.

Selanjutnya penelitian mengenai BLE yang dilakukan oleh Arief Sukma Indrayana[2], diperoleh kesimpulan bahwa performansi pengiriman data pada parameter delay melalui BLE dapat dipengaruhi oleh jarak. Semakin besar jarak, maka delay yang didapat juga menjadi semakin besar. Sedangkan pengaruh connection interval pada pengiriman data melalui BLE tidak terlalu besar karna pesan yang dikirim berukuran kecil.

Pada penelitian ini, penulis melakukan implementasi Bluetooth Low Energy sebagai media komunikasi pada sistem monitoring arus dan daya listrik. Penulis ingin mengetahui bagaimana performansi modul BLE saat diimplementasikan pada sistem monitoring daya listrik melalui aplikasi android.

\section{Listrik}

Listrik merupakan energi yang dapat disalurkan melalui penghantar berupa kabel, adanya arus listrik dikarenakan muatan listrik mengalir dari saluran positif ke saluran negatif.[3] Listrik sudah menjadi kebutuhan sehari-hari yang memiliki peran yang sangat penting. Peran listrik antara lain adalah sebagai sumber energi. Salah satu pemanfaatan listrik sebagai sumber energi yaitu pada rumah-rumah untuk peralatan elektronik.

\section{Listrik 1 fasa}

Listrik 1 fasa adalah instalasi listrik yang menggunakan dua kawat penghantar yaitu 1 kawat fasa dan 1 kawat 0 (netral). 
Pengertian sederhananya adalah listrik 1 fasa terdiri dari dua kabel yaitu 1 kabel bertegangan dan 1 netral. Umumnya listrik 1 fasa bertegangan 220 volt yang di gunakan banyak orang untuk listrik perumahan. Listrik PLN di jalanan memiliki 3 fasa, akan tetapi yang masuk ke perumahan hanya 1 fasa saja karena di dalam perumahan tidak memerlukan daya yang besar.[4]

\section{Bluetooth}

Bluetooth adalah sebuah teknologi komunikasi wireless yang beroperasi dalam pita frekuensi $2,4 \mathrm{GHz}$ unlicensed ISM (Industrial, Scientific and Medical) dengan menggunakan sebuah frequency hopping transceiver yang mampu menyediakan layanan komunikasi data dan suara secara real-time antara hosthost Bluetooth dengan jarak jangkauan layanan yang terbatas.[5]

\section{Bluetooth Low Energy}

BLE bekerja dengan menggunakan sinyal radio dengan modulasi GFSK pada pita frekuensi 2.4 GHz. BLE bekerja dengan lebar chanel $2 \mathrm{MHz}$ dengan menggunakan prinsip Frequency Hopping Spread Spectrum (FHSS).

Seperti teknologi Bluetooth klasik, stak protokol pada BLE terdiri atas 2 bagian utama, yaitu Controller dan Host. Pada Controller terdapat Physical Layer dan Link Layer, dan diimplementasikan sebagai System-on-Chip (SoC) dengan sebuah radio terintegrasi. Host berjalan pada sebuah prosesor dan terdapat beberapa layer fungsional seperti Logical Link Control and Adaptation Protocol (L2CAP), Atribute Protocol (ATT), Generic Attribute Profile (GATT), Security Manager Protocol (SMP) dan Generic Access Profile (GAP). Komunikasi antara Host dan Controller distandarisasi sebagai Host Controller Interface (HCI). [2]

\section{Modul BLE HM-10}

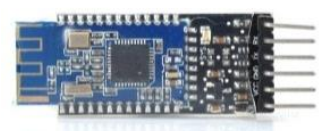

Gambar 1. Modul BLE HM-10

Modul BLE HM-10 bekerja pada voltase 3.3V atau 5V. Board HM-10 memiliki voltase yang terintegrasi (DC-DC) dan Logic Level Converters (LLC) sehingga pin-pinnya dapat langsung dihubungkan ke Arduino. HM-10 mengimplementasikan koneksi serial pada pin 1 (TXD) dan pin 2 (RXD) yang terhubung secara logika ke layanan dan koneksi BLE. Setiap data yang diterima melalui pin RXD dikirim melalui notifikasi ke perangkat pusat. Setiap data yang ditulis oleh perangkat pusat dilewatkan melalui pin TXD. Mekanisme ini menjadikan koneksi BLE sebagai koneksi serial standar untuk mikrokontroler yang terkoneksi.[6] Spesifikasi Modul Inti HM-10 :

- $\quad$ Power Supply : 3.3V hingga 5V

- Memenuhi spesifikasi Bluetooth v4.0 BLE

- Menggunakan IC SoC TI CC2540/1 dengan 256 KB Flash Memory dan 8 KB RAM

- Mengirim dan menerima data tanpa batasan ukuran (unlimited data size)

- Bekerja pada pita frekuensi 2,4 GHz ISM Band

- Modulasi GFSK (Gaussian Frequency Shift Keying)

- Mendukung moda transmisi data maupun moda pengendali jarak jauh/remote control
- Dapat berperan sebagai master atau slave, peran dipilih dengan AT Command ( $A T+R O L E$ )

- Daya siar dapat diatur antara $-23 \mathrm{dBm}$ hingga $6 \mathrm{dBm}$ lewat AT Command (AT+POWER)

- Kecepatan transisi data $6 \mathrm{Kbps}$ (pada mode asinkron maupun mode sinkron)

- Fitur keamanan dengan prosedur otentifikasi yang terenkripsi

- Layanan terpusat (central) \& peralatan UUID FFE0 FFE1

- Catu daya operasional 3,3 Volt DC dengan konsumsi arus $50 \mathrm{~mA}$

- Jarak komunikasi hingga 100 meter (pada udara tanpa hambatan)

- Konsumsi daya pada mode sleep kurang dari 1,5 mA, pada mode siaga $8,5 \mathrm{~mA}$

- $\quad$ Rentang suhu operasional $-5^{\circ} \mathrm{C} \sim+65^{\circ} \mathrm{C}$

\section{Android}

Android merupakan sistem operasi yang digunakan untuk perangkat mobile yang mencakup sistem operasi , middleware, dan aplikasi. Salah satu kelebihan android adalah bersifat Open Source, yang berarti bebas dikembangkan oleh siapapun tanpa dikenakan biaya terhadap sistem karena berbasis Linux. Para pembuat perangkat menyukai hal ini karena dapat membangun platform sesuai keinginan tanpa biaya royalti. Sementara pengembang software menyukainya karena android dapat digunakan diperangkat manapun tanpa terikat oleh segala vendor.[7]

\section{Mikrokontroler Arduino Uno}

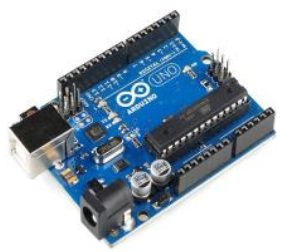

Gambar 2. Arduino Uno

Arduino Uno adalah salah satu varian mikrokontroler Arduino seberat 25 gram berbasis Atmega 328p. Memiliki 14 pin digital untuk input/output ( 6 untuk output PWM), 6 input analog, sebuah Kristal $16 \mathrm{MHz}$, koneksi USB, power jack, header ICSP, dan tombol reset. Beroperasi pada voltase $5 \mathrm{~V}$, dengan input yang direkomendasikan yaitu 7-12 V. [6]

Berikut spesifikasi arduino uno yang dapat dilihat pada Tabel 1.

Tabel 1. Spesifikasi Arduino Uno

\begin{tabular}{|l|l|}
\hline Mikrokontroler & ATmega 328 \\
\hline Operasi voltage & $5 \mathrm{~V}$ \\
\hline Input voltage & $7-12 \mathrm{~V}$ (Rekomendasi) \\
\hline Input voltage & $6-20 \mathrm{~V}$ (Limits) \\
\hline Pin I/O digital & 14 pin (6 pin untuk PWM) \\
\hline Pin input analog & 6 \\
\hline Arus DC untuk pin I/O & $40 \mathrm{~mA}$ \\
\hline Arus DC untuk pin 3,3V & $50 \mathrm{~mA}$ \\
\hline Flash memory & $32 \mathrm{~KB}$ \\
\hline SRAM & $2 \mathrm{~KB}$ \\
\hline EEPROM & $1 \mathrm{~KB}$ \\
\hline
\end{tabular}




\section{Clock speed}

$16 \mathrm{~Hz}$

\section{Sensor Arus SCT 013-000}

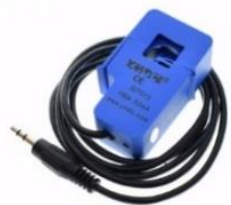

Gambar 3. Sensor SCT 013-000

Sensor SCT 013-000 adalah sensor yang digunakan untuk membaca seberapa besar nilai arus yang lewat pada suatu penghantar terhadap suatu beban. Prinsip kerja dasar dari sensor ini adalah sebuah penghantar yang dilewati oleh arus akan dilewatkan oleh sebuah ring toroid yang nantinya akan menimbulkan medan magnet, sehingga pada komponen sensor memiliki fluks magnet yang menginduksi kumparan di dalam sensor tersebut sehingga akan memunculkan sinyal listrik yang nantinya akan dibaca dan dikonversikan oleh arduino.[8] Spesifikasi sensor arus SCT 013-000 adalah sebagai berikut:

- Arus yang dapat dibaca : 0 100A AC

- Output arus : 0 55mA

- Resistance Grade : Grade B

- Standar panjang kabel : 1 meter

- Non-linearity : $\pm 3 \%$

- Turn Ratio : 100A:0.05A

- Suhu kerja : $-25^{\circ} \mathrm{C} \sim+70^{\circ} \mathrm{C}$

- Open size : $13 \mathrm{~mm}$ x $13 \mathrm{~mm}$

- Dielectric Strength (between shell and output) : 1000V $\mathrm{AC} / 1 \mathrm{~min} 5 \mathrm{~mA}$

\section{METODOLOGI PENELITIAN}

Penelitian Tugas Akhir ini merupakan jenis experimental research (penelitian percobaan). Dalam experimental research, subjek penelitian diberikan suatu treatment, kemudian dipelajari apa pengaruh treatment terhadap sistem dan subjek tersebut. Dalam hal ini, subjek penelitian merupakan kwh meter pada listrik prabayar dan treatment yang diberikan berupa monitoring daya listrik yang mengalir pada kwh meter.

\section{Rancangan Alat}

Bentuk rancangan alat sistem monitoring daya listrik dapat dilihat pada Gambar 4

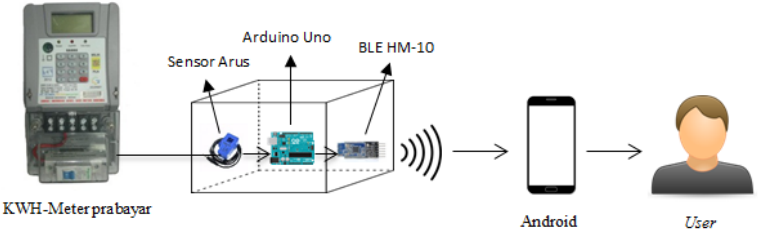

Gambar 4. Skema Rancangan Alat

Berdasarkan Gambar 4. Kwh meter dihubungkan dengan sensor arus untuk mendapatkan nilai arus yang nantinya akan dikirimkan ke mikrokontroler. Kemudian data dikirimkan melalui bluetooth ke aplikasi android. Pada aplikasi android user dapat memonitoring arus dan penggunaan daya listrik.

\section{Perancangan Perangkat Keras}

Sistem ini terdiri dari sebuah sensor arus SCT 013-000. Sensor ini menjadi alat untuk mendeteksi arus yang mengalir pada kwh meter. Nilai arus yang didapat nanti akan dikirimkan ke android melalui modul Bluetooth Low Energy. Untuk penggunaan daya pada kwh-meter, user dapat memonitoring nya melalui aplikasi android. Gambar 5 berikut ini merupakan perancangan perangkat keras dari sistem.

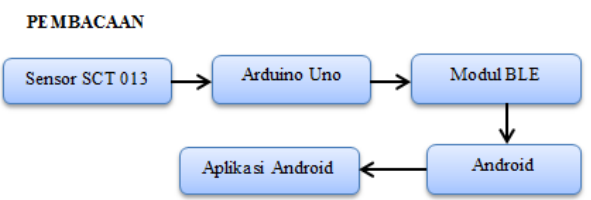

Gambar 5. Rancangan Perangkat Keras

Berdasarkan Gambar 5, berikut ini prinsip kerja masing-masing komponen :

a. Sensor

Sensor digunakan untuk mendeteksi nilai arus pada kwhmeter prabayar. Sensor yang digunakan pada sistem ini adalah sensor arus SCT 013-010.

b. Arduino Uno

Arduino UNO digunakan sebagai mikrokontroler yang menjadi pengontrol utama dari sistem, yang nantinya akan mengolah masukan yang telah dibaca oleh sensor, dan melakukan aksi sesuai program.

c. Modul BLE

Modul BLE digunakan sebagai media komunikasi dalam pengiriman data.

d. Android

Android digunakan sebagai platform untuk komunikasi dalam sistem monitoring.

e. Aplikasi android

Aplikasi android berguna sebagai user interface untuk menampilkan arus dan daya listrik, sehingga dapat dimonitoring oleh user.

\section{Rancangan Proses}

Rancangan proses yang dilakukan dapat dilihat pada Gambar 6 sebagai berikut: 


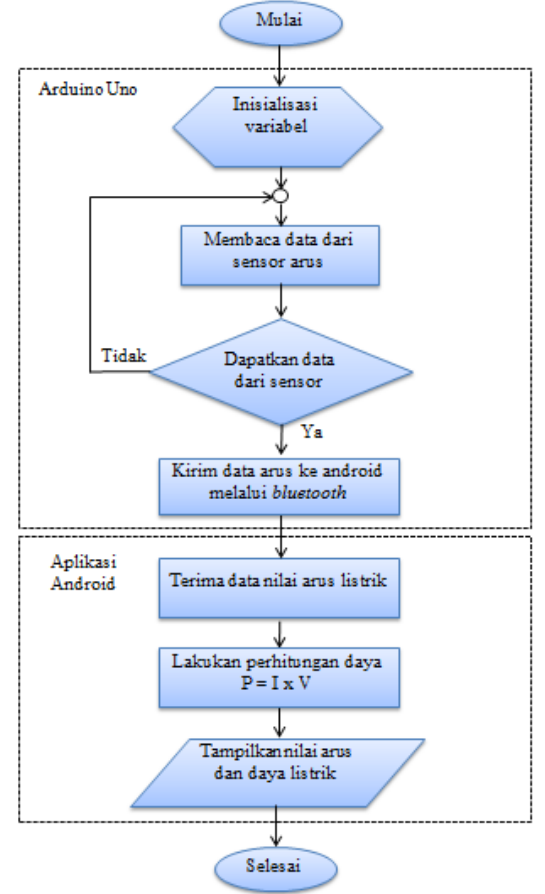

Gambar 6. Flowchart Rancangan Proses Sistem

Proses dimulai dengan menginisialisasikan variabel yang akan digunakan. Kemudian dilakukan pembacaan data nilai arus oleh sensor. Jika pembacaan data berhasil dilakukan, maka data akan dikirimkan ke mikrokontroler. Kemudian mikrokontroler akan mengirimkan data nilai arus ke android melalui modul BLE. Pada pemrograman aplikasi android dilakukan perhitungan untuk mendapatkan nilai daya listrik. User dapat memonitoring arus dan penggunaan daya listrik pada kwh meter melalui aplikasi android.

\section{HASIL DAN PEMBAHASAN}

\section{Implementasi Perangkat Keras}

Sistem monitoring daya listrik ini dibangun dengan menggunakan perangkat keras berupa sensor arus SCT 013-010, mikrokontroler Arduino Uno, dan modul BLE. Kabel sensor arus, Arduino Uno dan modul BLE dirangkai dan diletakkan pada sebuah kotak di dekat kwh meter seperti terlihat pada Gambar 7 berikut.

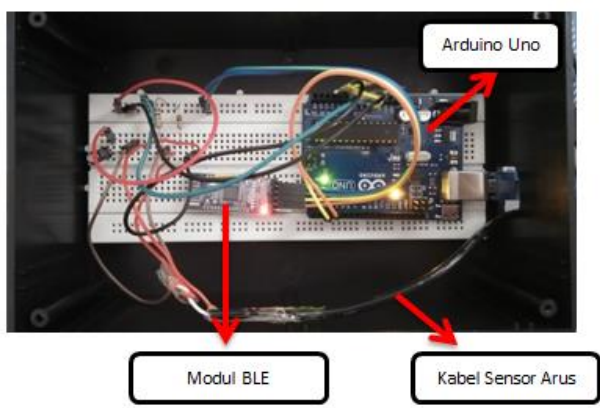

Gambar 7. Kotak Sistem

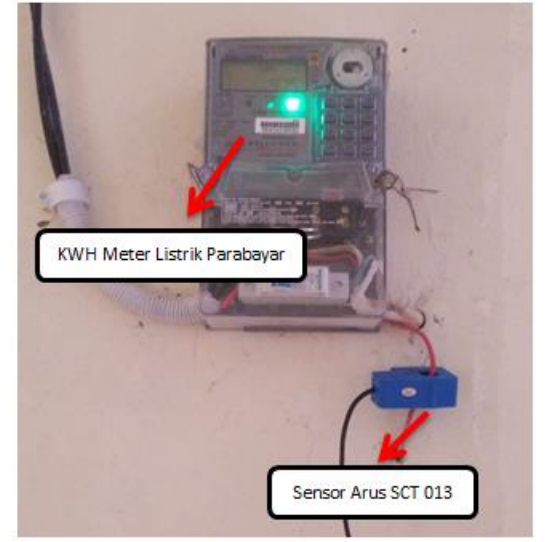

Gambar 8. Implementasi Perangkat Keras

Pada Gambar 8 terdapat kwh meter prabayar dan sensor arus. Sensor arus dipasangkan pada kabel phasa dari kwh meter yang menuju ke beban (rumah).

Penjelasan masing-masing komponen :

a. Arduino Uno, berfungsi sebagai mikrokontroler yang memproses seluruh kerja dari sistem yang dirancang.

b. Modul BLE, berfungsi sebagai media komunikasi yang akan mengirimkan data ke android.

c. Sensor arus SCT 013-000, berfungsi sebagai pendeteksi arus listrik pada kwh meter.

\section{Implementasi Aplikasi Android}

Implementasi aplikasi android berfungsi sebagai user interface untuk memonitoring arus dan penggunaan daya listrik pada kwh meter. Aplikasi android memiliki satu buah halaman yang berisi menu memonitorig. Menu monitoring merupakan menu tempat user memonitoring arus dan daya listrik. Terdapat button scan, disconnect, dan connect to master untuk menghubungkan aplikasi ke modul bluetooth. Selanjutnya terdapat indikator status bluetooth, apakah terkoneksi atau tidak. Nilai arus dan daya listrik akan ditampilkan pada textbox 1 dan textbox 2 . Bagian paling bawah terdapat button exit yang digunakan untuk keluar dari aplikasi. Berikut merupakan tampilan menu monitoring yang dapat dilihat pada Gambar 9.

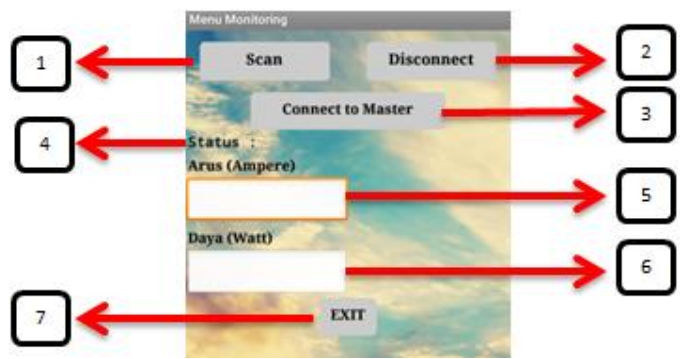

Gambar 9. Tampilan Aplikasi Android Keterangan :

1. Button Scan, digunakan untuk mencari perangkat bluetooth yang tersedia. Kemudian dapat dipilih bluetooth yang ingin dikoneksikan.

2. Button Disconnect, digunakan untuk memutuskan koneksi bluetooth.

3. Button Connect to Master, digunakan untuk langsung terkoneksi dengan perangkat bluetooth yang telah diketahui address nya dan di setting pada program.

4. Status, berfungsi sebagai indikator koneksi bluetooth apakah terkoneksi atau tidak. 
5. Textbox 1 , berfungsi untuk menampilkan nilai arus yang dibaca oleh sensor.

6. Textbox2, berfungsi untuk menampilkan nilai daya yang telah dilakukan perhitungan dengan mengalikan nilai arus yang diterima dari sensor dengan nilai tegangan standar listrik 1 phasa yaitu 220 volt.

7. Button Exit, digunakan untuk keluar dari aplikasi.

\section{Pengujian Sensor Arus SCT 013-000}

Pengujian ini dilakukan untuk mengetahui apakah nilai arus listrik yang dibaca oleh sensor sama dengan yang diukur dengan kwhmeter agar didapat tingkat keakuratan sensor. Pengujian dilakukan dengan melakukan 10 kali percobaan yang ditampilkan pada tabel 2 berikut.

Tabel 2. Pengujian Sensor Arus

\begin{tabular}{|c|c|c|c|}
\hline $\begin{array}{c}\text { Percobaan } \\
\text { Ke }\end{array}$ & $\begin{array}{c}\text { Arus listrik } \\
\text { pada } \\
\text { kwhmeter } \\
\text { (A) }\end{array}$ & $\begin{array}{c}\text { Arus } \\
\text { listrik } \\
\text { yang } \\
\text { bibaca } \\
\text { sensor } \\
\text { (A) }\end{array}$ & $\begin{array}{c}\text { Selisih } \\
\text { Pengukuran } \\
\text { (A) }\end{array}$ \\
\hline 1 & 0,25 & 0,24 & 0,01 \\
\hline 2 & 0,27 & 0,27 & 0,00 \\
\hline 3 & 0,16 & 0,14 & 0,02 \\
\hline 4 & 0,09 & 0,09 & 0,00 \\
\hline 5 & 0,18 & 0,18 & 0,00 \\
\hline 6 & 0,15 & 0,11 & 0,04 \\
\hline 7 & 0,25 & 0,22 & 0,03 \\
\hline 8 & 0,20 & 0,20 & 0,00 \\
\hline 9 & 0,29 & 0,25 & 0,04 \\
\hline 10 & 0,26 & 0,25 & 0,01 \\
\hline \multicolumn{3}{|l|}{$\sum$ Selisih Pengukuran } & 0,15 \\
\hline
\end{tabular}

Berdasarkan pengujian di atas, dapat dilihat bahwa pengukuran arus oleh sensor memiliki nilai yang tidak terlalu jauh berbeda dengan pengukuran arus menggunakan kwhmeter Selisih pengukuran terkecil bernilai 0,00 yang artinya sensor dapat membaca nilai arus $100 \%$ benar. Sedangkan selisih pengukuran terbesar bernilai 0,04. Dari tabel diatas dapat diketahui nilai rata-rata selisih pengukuran dari pengujian yang dilakukan adalah sebagai berikut.

Rata - rata selisih pengukuran $=\frac{\sum(\text { selisih pengukuran })}{(\text { jumlah pengujian })}$

Rata - rata selisih pengukuran $=\frac{\sum(0,15)}{(10)}$

Rata - rata selisih pengukuran $=0,015$

Dari tabel 2 didapatkan grafik hasil pengujian seperti pada Gambar 10 berikut ini.

\section{Pengukuran Nilai Arus}

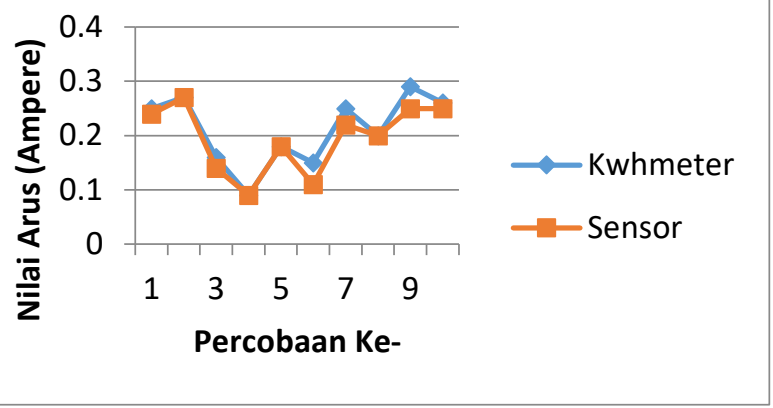

Gambar 10. Grafik Pengukuran Nilai Arus

\section{Pengujian Modul BLE Dari Segi Waktu}

Pengujian ini dilakukan untuk mengetahui delay waktu dalam pengiriman data dari modul BLE hingga peneriman data oleh android dalam rentang jarak yang berbeda tanpa halangan. Pengujian dilakukan dengan 15 kali percobaan pengiriman data dengan jarak 1 meter, 5 meter, dan 10 meter dengan masingmasing percobaan dilakukan sebanyak 5 kali. Hasil dari pengujian dapat dilihat pada Tabel 3 .

Tabel 3. Pengujian Modul BLE Dari Segi Waktu Pegiriman Data

\begin{tabular}{|c|c|c|}
\hline Percobaan & Jarak & $\begin{array}{l}\text { Waktu delay } \\
\text { (millisecond) }\end{array}$ \\
\hline 1 & \multirow{5}{*}{1 meter } & 1261 \\
\hline 2 & & 1264 \\
\hline 3 & & 1263 \\
\hline 4 & & 1264 \\
\hline 5 & & 1264 \\
\hline 6 & \multirow{5}{*}{5 meter } & 1262 \\
\hline 7 & & 1264 \\
\hline 8 & & 1263 \\
\hline 9 & & 1263 \\
\hline 10 & & 1264 \\
\hline 11 & \multirow{5}{*}{10 meter } & 1262 \\
\hline 12 & & 1264 \\
\hline 13 & & 1264 \\
\hline 14 & & 1263 \\
\hline 15 & & 1263 \\
\hline
\end{tabular}

Dari pengujian yang telah dilakukan dapat dilihat bahwa rata-rata delay waktu yang dibutuhkan modul bluetooth untuk mengirim data ke android adalah 1264 millisecond atau 1,264 detik dari jarak 1 meter hingga jarak 10 meter. Sehingga dapat diambil kesimpulan bahwa delay waktu pengiriman data oleh modul BLE tidak bergantung terhadap jarak. Selama koneksi bluetooth masih terhubung, maka delay waktu pengiriman datanya akan bernilai sama.

\section{Pengujian Modul BLE Dari Segi Jarak}

Pengujian ini dilakukan untuk mengetahui jarak maksimal komunikasi modul BLE dibandingkan dengan modul HC-05 
dalam kondisi saat tanpa halangan yang dapat dilihat pada Tabel 4 dan saat ada halangan seperti dinding yang dapat dilihat pada Tabel 5. Pengujian dilakukan sebagai berikut.

Tabel 4. Pengujian Modul Bluetooth Dari Segi Jarak Tanpa Halangan

\begin{tabular}{|c|c|c|c|}
\hline \multirow{2}{*}{$\begin{array}{l}\text { Percobaan } \\
\text { ke }\end{array}$} & $\begin{array}{c}\text { Jarak } \\
(\mathbf{m})\end{array}$ & Modul BLE & HC-05 \\
\cline { 3 - 4 } & & Respon & Respon \\
\hline 1 & 3 & Berhasil & Berhasil \\
\hline 2 & 6 & Berhasil & Berhasil \\
\hline 3 & 9 & Berhasil & Berhasil \\
\hline 4 & 12 & Berhasil & Berhasil \\
\hline 5 & 15 & Berhasil & Berhasil \\
\hline 6 & 18 & Berhasil & Berhasil \\
\hline 7 & 21 & Berhasil & $\begin{array}{c}\text { Tidak } \\
\text { Berhasil }\end{array}$ \\
\hline 8 & 24 & Berhasil & $\begin{array}{c}\text { Tidak } \\
\text { Berhasil }\end{array}$ \\
\hline 9 & 27 & $\begin{array}{c}\text { Tidak } \\
\text { Berhasil }\end{array}$ & $\begin{array}{c}\text { Tidak } \\
\text { Berhasil }\end{array}$ \\
\hline 10 & 30 & $\begin{array}{c}\text { Tidak } \\
\text { Berhasil }\end{array}$ & $\begin{array}{c}\text { Tidak } \\
\text { Berhasil }\end{array}$ \\
\hline
\end{tabular}

Tabel 5 Pengujian Modul Bluetooth Dari Segi Jarak Ada Halangan

\begin{tabular}{|c|c|c|c|}
\hline $\begin{array}{c}\text { Percobaan } \\
\text { ke }\end{array}$ & Jarak (m) & Modul BLE & HC-05 \\
\cline { 2 - 4 } & Respon & Respon \\
\hline 1 & 1 & Berhasil & Berhasil \\
\hline 2 & 3 & Berhasil & Berhasil \\
\hline 3 & 5 & Berhasil & Berhasil \\
\hline 4 & 7 & Berhasil & $\begin{array}{c}\text { Tidak } \\
\text { Berhasil }\end{array}$ \\
\hline 5 & 9 & $\begin{array}{c}\text { Tidak } \\
\text { Berhasil }\end{array}$ & $\begin{array}{c}\text { Tidak } \\
\text { Berhasil }\end{array}$ \\
\hline
\end{tabular}

Berdasarkan percobaan diatas, untuk mengetahui jarak yang dapat dijangkau oleh modul BLE dilihat respon modul pada rentang jarak yang berbeda dan dalam kondisi yang berbeda, yaitu tanpa halangan dan ada halangan. Pada kondisi tanpa halangan, modul BLE berhasil meberi respon hingga jarak 25 meter. Pada jarak 27 meter modul tidak berhasil saling terkoneksi. Sedangkan untuk modul HC-05, bluetooth masih terkoneksi hingga jarak 19 meter Pada kondisi adanya halangan, modul BLE dan android dapat saling terkoneksi hingga jarak 8 meter. Pada jarak 9 meter modul tidak berhasil memberikan respon. Sedangkan pada modul HC-05 koneksi bluetooth mencapai jarak 6 meter. Hal ini menunjukkan bahwa jarak yang dapat dijangkau oleh modul BLE sangat berpengaruh terhadap adanya halangan seperti dinding yang dapat mempersingkat jarak jangkauan modul. Pengujian dilakukan pada lorong yang panjang di dalam ruangan, sehingga pada bagian sisi kiri dan kanan terdapat dinding. Inilah yang dianggap sebagai penyebab jarak jangkauan modul BLE hanya mencapai 25 meter.

\section{Pengujian Modul BLE Dari Segi Keakuratan Data}

Pengujian ini dilakukan untuk mengetahui nilai arus listrik yang dibaca oleh sensor sama dengan yang dikirimkan oleh modul bluetooth agar didapat tingkat keakuratan data. Pengujian dilakukan dengan 10 kali percobaan perbandingan seperti yang ditampilkan pada Tabel 6 berikut.

Tabel 6. Pengujian Modul BLE Dari Segi Keakuratan Data

\begin{tabular}{|c|c|c|c|}
\hline $\begin{array}{c}\text { Percobaan } \\
\text { Ke }\end{array}$ & $\begin{array}{c}\text { Arus listrik } \\
\text { yang } \\
\text { dibaca } \\
\text { sensor (A) }\end{array}$ & $\begin{array}{c}\text { Arus listrik } \\
\text { yang dikirim } \\
\text { oleh modul } \\
\text { BLE (A) }\end{array}$ & $\begin{array}{c}\text { Selisih nilai } \\
\text { arus (A) }\end{array}$ \\
\hline 1 & 0,09 & 0,09 & 0,00 \\
\hline 2 & 0,13 & 0,13 & 0,00 \\
\hline 3 & 0,15 & 0,15 & 0,00 \\
\hline 4 & 0,15 & 0,15 & 0,00 \\
\hline 5 & 0,37 & 0,37 & 0,00 \\
\hline 6 & 0,35 & 0,35 & 0,00 \\
\hline 7 & 0,45 & 0,45 & 0,00 \\
\hline 8 & 1,03 & 1,03 & 0,00 \\
\hline 9 & 1,15 & 1,15 & 0,00 \\
\hline 10 & 1,34 & 1,34 & 0,00 \\
\hline
\end{tabular}

Dari percobaan yang telah dilakukan, didapatkan hasil yang menyatakan bahwa modul bluetooth dapat mengirimkan data sesuai dengan yang dibaca oleh sensor. Sehingga tingkat keakuratan data yang dikirim adalah sebesar $100 \%$.

\section{Pengujian Konsumsi Energi}

Pengujian dilakukan untuk mengetahui penggunaan energi (daya) pada saat mengoperasikan modul BLE dibandingkan dengan bluetooth HC-05. Pengujian dilakukan sebanyak 10 kali percobaan dengan cara mengukur nilai arus dan tegangan pada masing-masing bluetooth menggunakan multimeter. Kemudian dilakukan perhitungan untuk mendapatkan nilai daya dengan menggunakan persamaan :

$$
\mathrm{P}=\mathrm{I} \times \mathrm{V}
$$

Keterangan :

$\mathrm{P}=$ Daya $($ Watt $)$

$\mathrm{I}=$ Arus (Ampere)

$\mathrm{V}=$ Tegangan $($ Volt $)$

Nilai tegangan yang digunakan adalah tegangan standar untuk listrik 1 fasa yaitu 220 volt.

Pada tabel 7 diperlihatkan hasil pengujian konsumsi energi pada modul BLE dan modul HC-05.

Tabel 7. Pengujian Konsumsi Energi Modul Bluetooth

\begin{tabular}{|c|c|c|c|c|c|c|}
\hline \multirow{2}{*}{$\begin{array}{c}\text { Percobaan } \\
\text { Ke- }\end{array}$} & \multicolumn{3}{|c|}{ Modul HC-05 } & \multicolumn{3}{|c|}{ Modul BLE } \\
\hline & $\begin{array}{l}\text { Arus } \\
(\mathrm{mA})\end{array}$ & $\begin{array}{l}\text { Tegangan } \\
\text { (V) }\end{array}$ & $\begin{array}{l}\text { Daya } \\
\text { (mW) }\end{array}$ & $\begin{array}{l}\text { Arus } \\
\text { (mA) }\end{array}$ & $\begin{array}{l}\text { Tegangan } \\
\text { (V) }\end{array}$ & $\begin{array}{l}\text { Daya } \\
(\mathrm{mW})\end{array}$ \\
\hline 1 & 2,6 & 5,06 & 13,156 & 1,1 & 4,97 & 5,467 \\
\hline 2 & 2,5 & 5,02 & 12,55 & 1,1 & 5,02 & 5,522 \\
\hline 3 & 2,7 & 5,04 & 13,608 & 1,1 & 4,98 & 5,478 \\
\hline 4 & 2,7 & 5,08 & 13,716 & 1,2 & 4,98 & 5,976 \\
\hline 5 & 2,7 & 5,22 & 14,094 & 1,1 & 5,15 & 5,665 \\
\hline 6 & 2,6 & 5 & 13 & 1,1 & 4,96 & 5,456 \\
\hline 7 & 2,7 & 5,02 & 13,554 & 1,1 & 5 & 5,5 \\
\hline 8 & 2,7 & 5,08 & 13,716 & 1,2 & 5,08 & 6,096 \\
\hline 9 & 2,7 & 5,07 & 13,689 & 1,2 & 5,04 & 6,048 \\
\hline \multirow[t]{2}{*}{10} & 2,7 & 5,06 & 13,662 & 1,2 & 5,06 & 6,072 \\
\hline & \multicolumn{2}{|c|}{ Rata-rata } & 13,47 & \multicolumn{2}{|c|}{ Rata-rata } & 5,728 \\
\hline
\end{tabular}


Dari tabel di atas dapat dilihat rata-rata konsumsi energi modul HC-05 adalah sebesar 13,47 mW. Yang mana angka ini lebih besar jika dibandingkan dengan konsumsi energi oleh modul BLE yang hanya mengkonsumsi daya sebesar $5,728 \mathrm{~mW}$. Sehingga dapat disimpulkan bahwa modul BLE lebih hemat dalam penggunaan energi.

\section{Pengujian Pembacaan Nilai Arus}

Pengujian ini dilakukan untuk membandingkan nilai arus yang dilihat pada kwh meter dan yang ditampilkan pada aplikasi. Tabel dibawah menunjukkan perbedaan pembacan nilai arus. Pengujian dilakukan pada perangkat elektronik berbeda yang dicolokkan pada stop kontak. Kemudian dilakukan pembacaan nilai arus pada aplikasi dan kwh meter. Berikut hasil pengujian pembacaan nilai arus yang dapat dilihat pada Tabel 8 .

Tabel 8. Pengujian Pembacaan Nilai Arus

\begin{tabular}{|c|c|c|c|c|}
\hline $\begin{array}{c}\text { Percobaan } \\
\text { ke- }\end{array}$ & $\begin{array}{c}\text { Arus yang } \\
\text { diukur pada } \\
\text { kwh meter (A) }\end{array}$ & $\begin{array}{c}\text { Arus yang } \\
\text { tampilkan pada } \\
\text { aplikasi (A) }\end{array}$ & $\begin{array}{c}\text { Selisih } \\
\text { Pengukuran } \\
\text { (A) }\end{array}$ & $\begin{array}{c}\text { Error } \\
(\%)\end{array}$ \\
\hline 1 & 0,884 & 0,90 & 0,016 & 1,778 \\
\hline 2 & 0,715 & 0,72 & 0,005 & 0,694 \\
\hline 3 & 0,736 & 0,76 & 0,024 & 3,157 \\
\hline 4 & 0,654 & 0,69 & 0,036 & 5,217 \\
\hline 5 & 2,049 & 2,06 & 0,011 & 0,533 \\
\hline 6 & 0,936 & 0,94 & 0,004 & 0,425 \\
\hline 7 & 0,710 & 0,74 & 0,030 & 4,054 \\
\hline 8 & 2,225 & 2,28 & 0,055 & 2,412 \\
\hline 9 & 0,722 & 0,76 & 0,038 & 5 \\
\hline 10 & 0,678 & 0,70 & 0,022 & 3,142 \\
\hline \multicolumn{4}{|c|}{$\sum$ error } & 26,412 \\
\hline \multicolumn{4}{|c|}{ Rata-rata Error } & 2,641 \\
\hline
\end{tabular}

Dari Tabel 8 dapat dilihat perbedaan pengukuran dari sensor arus dengan yang ditampilkan pada kwh meter. Selisih pengukuran tertinggi terjadi pada saat percobaan ke-8 dengan selisih pengukuran sebesar 0,055 ampere dan selisih terendah terjadi pada saat percobaan ke-6 dengan selisih pengukuran 0,004 ampere. Sedangkan nilai error tertinggi terjadi pada saat percobaan ke-4 dengan nilai error sebesar 5,217\% dan terendah terjadi pada saat percobaan ke-6 dengan nilai error $0,425 \%$. Berikut merupakan presentase error rata-rata pada pengujian sensor arus.

$$
\begin{gathered}
\text { Error rata }- \text { rata }=\frac{\sum(\text { Error })}{(\text { jumlah data })} \\
\text { Error rata }- \text { rata }=\frac{\sum(26,412)}{(10)} \\
\text { Error rata }- \text { rata }=2,641 \%
\end{gathered}
$$

Dari hasil pengujian diatas juga dapat diambil kesimpulan bahwa nilai error rata-rata yang didapat adalah sebesar $2,641 \%$. Nilai ini didapatkan berdasarkan jumlah total semua nilai error dibagi dengan banyak nya data yang diambil atau banyak nya percobaan.

\section{Pengujian Kerja Aplikasi Android}

Nilai arus dan daya listrik akan ditampilkan pada textboxl dan textbox2. Berikut pada Gambar 11 merupakan tampilan monitoring arus dan daya listrik pada aplikasi android.

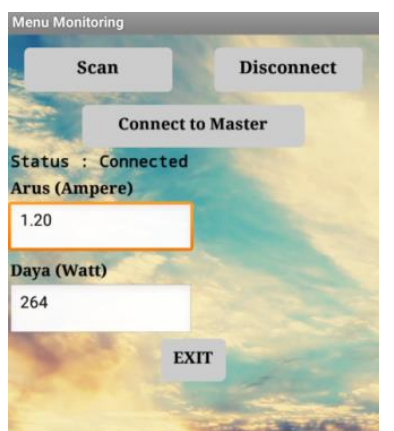

Gambar 11. Tampilan Monitoring Arus dan Daya Listrik Dari Gambar 11, nilai arus yang terbaca oleh aplikasi adalah sebesar 1,20 ampere dan nilai daya listrik adalah 264 watt. Pembacaan data dilakukan secara real time, sehingga data akan terus berubah tiap satu detik.

\section{KESIMPULAN}

Berdasarkan penelitian dan pengujian yang telah dilakukan, maka dapat diambil kesimpulan sebagai berikut:

1. Sistem monitoring yang dirancang mampu melakukan monitoring nilai arus dan daya listrik secara real time melalui aplikasi pada android dengan presentase error rata-rata 2,641\%.

2. Modul BLE dapat digunakan sebagai media komunikasi dalam pengiriman data dengan hasil pengujian kinerja modul BLE dapat dilihat seperti dibawah ini:

- Waktu, delay pengiriman data rata-rata adalah 1264 millisecond atau 1,264 detik.

- Jarak, jarak terjauh jangkauan modul BLE dalam kondisi tanpa halangan (dinding) adalah 25 meter, dan 8 meter untuk kondisi ada halangan.

- Keakuratan data, tingkat keakuratan data yang dikirimkan oleh modul bluetooth adalah senilai $100 \%$.

- Rata-rata konsumsi energi modul BLE lebih hemat dibandingkan dengan konsumsi energi modul bluetooth HC-05 dengan perbandingan modul BLE sebesar 5,728 $\mathrm{mW}$ dan modul HC-05 adalah sebesar 13,47 mW.

\section{SARAN}

Mengingat masih terdapat beberapa kekurangan dalam penelitian ini, maka perlu dilakukan perbaikan untuk lebih mengoptimalkan kinerja sistem, antara lain:

1. Untuk penelitian selanjutnya agar dapat mengimplementasikan teknologi IoT pada sistem agar monitoring dapat dilakukan dari jarak jauh menggunakan jaringan internet.

2. Untuk penelitian selanjutnya agar dapat membuat aplikasi yang bersifat multiuser.

3. Untuk penelitian selanjutnya agar dapat meningkatkan sistem tidak hanya sekedar memonitoring tapi juga bisa melakukan pengisian token listrik dengan melakukan kerjasama dengan pihak PLN. 


\section{REFERENCES}

[1] Afriadi. 2017. Sistem Kendali Pemakaian Listrik Peralatan Elektronik Rumah Tangga Berbasis Android Menggunakan Sensor Arus. Padang : Universitas Andalas.

[2] Indrayana, Arief Sukma, dkk. 2017. Rancang Bangun Sistem Komunikasi Bluetooth Low Energy (BLE) Pada Sistem Pengamatan Tekanan Darah. Malang : Universitas Brawijaya.

[3] Zulpa, Ariefman. 2015. Prototype Monitoring Pengukuran Beban dan Biaya Arus Listrik dengan Mikrokontroler Arduino pada Pelanggan Pascabayar Berbasis Web. Jakarta : Universitas Islam Negeri Syarif Hidayatullah.

[4] Putra, Komang Deliana. 2016. Teknologi Energi Listrik. Malang : Institut Teknologi Nasional.

[5] Sukamto, Victorio. 2011. Teknologi Bluetooth dan Aplikasinya Terhadap Jaringan Komputer. Semarang : Universitas AKI.

[6] Naghi, I Wayan Boby Astagina, dkk. 2017. Implementasi Sistem Pervasive Pada Smarthome Berbasis Bluetooth Versi 4.0 Menggunakan Modul BLE HM-10 dan Sensor. Malang : Universitas Brawijaya.

[7] Yuniar, Supriadi. 2014. Semua Bisa Menjadi Programmer Android. Elex Media : Bandung

[8] Wildani, Erick Pratama. 2017. Rancang Bangun Sistem Monitoring Penggunaan Daya Listrik Di Rumah Tangga. Yogyakarta : Universitas Muhammadiyah Yogyakarta. 